Article

\title{
Effect of Multiple Layers of Carbon Fiber Reinforced Polymer on Flexural Strength of Reinforced Concrete
}

\author{
Ali Raza Khoso ${ }^{1}$, Muhammad Akram Akhund ${ }^{2}$, Shankar Lal Menghwar ${ }^{1}$ and Fida Hussain \\ Siddiqui ${ }^{1}$ \\ 1 Civil Engineering Department, Mehran University of Engineering Technology, Jamshoro Sindh, Pakistan \\ aliraza.khoso@faculty.muet.edu.pk, fida.siddiqui@faculty.muet.edu.pk, shanker.lal@faculty.muet.edu.pk \\ 2 Civil Engineering Department, ISRA University, Hyderabad \\ akhund42@gmail.com, ma.akhund@isra.edu.pk \\ * Correspondence: akhund42@gmail.com; Tel.: +92-333-722-2078
}

\begin{abstract}
Concrete is a very common construction material. As time prevails, cracks often appear in structures that pose a threat to strength and durability, which ultimately affect the structural integrity of concrete. Extensive work has been carried out in past on utilization of Carbon Fiber Reinforced Polymer (CFRP) as a repair material. But, this research particularly focuses on: multiple fiber layers i.e. single and double, traditional concrete mix ratio with locally available materials and varying flexural reinforcement. Furthermore, this work presents an experimental analysis to strengthen the Reinforced Concrete (RC) beams using SikaWrap- 230 C as a CFRP wrap, and Sikadur-330 as a bonding material. The comparison between single and double layers of CFRP is of major interest in this research. Six reinforced concrete beams were repaired with CFRP and tested under three-point bending test. For these specimens, load deflection behavior along with crack propagation and failure of beams were studied. Experimental results show that beams repaired using CFRP wrapping achieved higher flexural capacity and ductility as compared with reference beam. Moreover, results reveal that introduction of second layer of fiber caused around $4-5.2 \%$ increment in flexural strength and resulted in higher ductility of RCC beam.
\end{abstract}

Keywords: CFRP; Double layers of CFRP; Concrete Repair; Flexural Behavior; Load Deflection Curve

\section{Introduction}

Reinforced cement concrete is the most frequently used structural material due to its good durability and higher compressive strength. It is extensively used in the variety of civil infrastructures including small and large buildings, houses, bridges, storage tanks, dams and numerous other types of structures [1]. For flexural members in structure, the flexural design is important, as bending stresses in such members cause serious damages in the form of micro and macro cracks due to lower tensile strength of concrete, which subsequently require structure re-strengthening. Furthermore, various other causes have been investigated in past for deterioration of concrete such as corrosion of steel, aging of concrete, sudden loading, earthquake, environmental effects, overloading etc. The repair of such structurally deteriorated reinforced concrete structures becomes necessary as the structural element ceases to provide satisfactory over loading, strength, and serviceability.

Historically, steel plate, cement sand grout and post tensioning methods were used for repairing purpose, which was not so much efficient for higher loading [2]. Repairing of Reinforced Concrete (RC) structures with externally bonded Fiber Reinforced Polymer (FRP) started in 1980 $[3,4]$ and then number of experiment and research work has been performed in the last three decades on the use of composite materials for the re-strengthening of reinforced concrete structures $[5,6]$ Jones et al., 1980 [11], Saadatmanesh and Ehsani, 1991[12], Chajes et al., 1994 [13], Arduini et al., 1997 [14], Norris et al., 1997 [15], Yeong-soo and Chadon, 2003 [2]. 
The FRP reinforcement can be used for various RC structural members such as beams, slabs, columns and silos for their re-strengthening. It provides confinement and ductility to structures by enhancing load carrying, flexural and shear capacity [7].

Recent development in FRP and repairing materials has unlocked the new path for research in concrete technology. Due to this reason, diverse types of fibers and repairing materials are being used in construction industry for re-strengthening. Among those types, Carbon fibers with epoxy bonding is one of the recognized and very effective strengthening material, due to its numerous dominated properties over traditional techniques. Carbon fiber is available with brand name Carbon Fiber Reinforced Polymer (CFRP). It offers superior performance due to its inevitable properties such as high tensile strength, resistance to corrosion, light weight, high stiffness/weight ratio, long lasting life and ease in installation. The performance of CFPR is also depend on its bonding with concrete. Externally bonded CFRP sheets have been proven most common used techniques. But many investigations are witnessed that, a brittle failure occurs due to deboning of sheets i.e. peeling off the fibers. This cause is due to peeling stresses which is induced at the ends of sheets; when these stresses increase than the strength of adhesive the de-bonding take place [16].

In terms of experimental application, several studies have been performed to study the behavior of beams repaired using CFRP with different arrangements depending on behavior of structural member. Mahmut Ekenel, and John J. Myers [17] did a comprehensive research on combination of two different materials, epoxy and CFRP. Different cracked beams were strengthened and tested under aggressive environment with both materials separately. The study concludes that injection in cracks provide higher stiffness but no increment in flexural strength. Also epoxy injection is less effective under environmental conditions. When epoxy injection is combined with CFRP, it gave higher flexural strength and less cracking width.

A Shahawy et al. (2001) [4] investigated $20 \mathrm{ft}$ long RCC T-girders. A reference girder with two layers of CFRP wrap and a control girder without fiber wrapping were failed in testing. Initially the specimens were loaded up to $65 \%, 85 \%$ and $117 \%$ of failure load of controlled beam and the same time locked. The specimens were then repaired by two layers of CFRP and then resumed the loading till failure.

Study on deep beams repaired externally using CFRP laminates was investigated by Clayton A. Burningham et al (2015) [18], research concludes that, the ultimate load carrying capacity of tested specimen increased whereas there is no change observed in deflection. A similar type of experimental work has been presented by Omrane Benjeddou [19], where researcher used simple beam specimen instead of deep beams. CFRP was used in varying width and damage degree with different concrete class. The study examined that all type of repaired specimen has achieved higher strength and rigidity. However, the study recommended that for higher strength, CFRP with half width beam is highly effective. Hamidreza Tahsiri [20] measured the difference between effectiveness of FRP and RC jacketing for concrete repair purpose in terms of load-deflection behavior, failure modes and crack propagation patterns. The research concludes that RC jacketing beams were failed very similar to reference beams and FRP strengthen beams were failed in de bonding with small deflection. However, both techniques were effective in terms of ultimate strength.

Shufeng Liu et.al, 2016 examined the hygrothermal effects on adhesive material and CFRP double lap shear joint. The specimens were divided into different environment conditions and their effects was studied on specimen. The study presented that the elastic modulus and tensile strength varies with environmental conditions. Also it suggests that, at higher moisture absorption high degradation take place in tensile strength and elastic modulus. Moreover, shear strength was also dropped up to $54.5 \%$ due to humidity and elevated temperature [21].

An experimental study by Limam et al [22] proved that CFRP plates when externally bonded can strengthen two-way slab. Faza and Ganga [23] by their experimental research reported that CFRP when wrapped around beams can increase up to $200 \%$ in strength. The load history analysis is determined by Wang Wenwei \& Li Guo (2004) [24]. The researcher analyzed the effect of CFRP laminates on beams in terms of flexural behavior due to sustaining load. The research proved that 
CFRP is good in resisting the sustaining load by keeping the same initial load. Zachary B. Haber et al (2011) [25] investigated the mechanical and environmental loading effects on full scaled beams repaired with CFRP. The specimens were strengthened by two different binders i.e. epoxy and polyurethane matrix. The beams were tested under cyclic loading, uncontrolled outdoor environment, exposure, controlled thermal cycling and monotonic loading till failure. The research finally investigated that, epoxy is more sensitive to environmental conditions as compared to polyurethane matrix. However maximum deflection has observed in specimen strengthened with epoxy. Also, epoxy has more adhesive strength and less susceptible to de-bonding as compared to polyurthene.

Francesco Capani et al., 2017 [28] determined the cyclic response of CFRP repaired beams. The study incorporated the level of axial load strengthening configuration and level of initial damage. The results explain that CFRP has better mechanical response and is very effective in controlling the cyclic loading. A recent study has been done on application of CFRP on steel concrete composite beams by Ehab C. Karam, 2017[29]. The beams were strengthened using external bonding of CFRP with and without mechanical bonding. The research presents that, CFRP is able to restore the actual strength of beam. Moreover, provision of mechanical anchor enhances the performance of fiber. De bonding is a major concern in CFRP sheets due to lustry and fair surface of structural components. Binding material is not able to create the strong bond between the surface of structural member and strengthening material like CFRP. To control this de bonding various research has been carried out in past such as, steel grooving, steel riveting, cement paste, U wrapping of CFRP, roughening of beams for FRP placement etc. Alaa Morsy \& El Tony Mahmoud 2012 [26] tested various beams for de bonding using epoxy and steel rivet and combination of rivet and epoxy but all specimens failed in de bonding.

Vladimir José Ferrari (2013) [27], utilized High Performance Fiber Reinforcement Cement-based Composite (HPFRCC) as matrix or bonding material. The results were satisfactory and HPFRCC was recommended as bonding material for CFRP. Furthermore, CFRP due to its numerous advantages can be applied to arches (Xu Zhang, 2015) [30], timber beams (Angelo D'Ambrisi, 2013) [31], two-way slabs (Limam et al) [22], beam-column joints (Mohamed H. Mahmoud et al, 2013) [32] for re-strengthening.

On commercial level, the CFRP is being produced in thin layers, which does not result in higher strength and ductility when applied in single layer for strengthening. For this reason, there is strong need of such a mechanism for its effective utilization to increase the mechanical properties like flexural strength and ductility. As an alternate of increasing fiber thickness, multiple layers can be adopted by providing another layer over the first one. This work has focused on different layers system of CFRP on flexural re strengthening. Thus, main aim of this work is to strengthen the RCC beams using single and double layer of fiber with a strong adhesive, sikadur-330.

\section{Research Aim and Scope}

\subsection{Aim}

This research aims to assess the behavior of multiple layers of CFRP on flexural strength of RCC beam. The strengthened beams were compared in terms of their flexural strength and ductility with controlled beam to check the layer effect.

\subsection{Scope}

The scope of this research is limited to following:

- All specimens were designed to fail in bending at same water-cement (W/C) and mix ratio i.e. 1:2:4 mix ratio and 0.50 W/C-ratio.

- Only flexural behavior of beams was investigated.

- Locally available CFRP with brand name "SikaWrap -230 C" and an adhesive, "Sikadur-303" used for this study. 


\section{Experimental Investigation}

149

150

151

152

153

154

155

156

157

158

159

160

161

162

163

164

165

166

167

\subsection{Material Properties}

Locally available materials are used for this research. Ordinary Portland cement (OPC) with brand name "Lucky Cement" used as binding material for manufacturing of concrete. The fine aggregates used are natural hill sand having fineness modulus 3.72 and unit weight $1850 \mathrm{~kg} / \mathrm{m} 3$. Coarse aggregates used for this study are crushed and angular in shape with nominal size of $20 \mathrm{~mm}$, having fineness modulus of 4.46 and unit weight of $1580 \mathrm{~kg} / \mathrm{m} 3$. Deformed steel having grade 60 i.e. 60,000psi yield strength is used for reinforcement of beam. Carbon Fiber Reinforced Polymer with brand name "SikaWrap-230 C" and epoxy adhesive with brand name "Sikadur-330" were used and their basic properties are given in Table $1 \&$ Table 2 . The 28 days compressive strength of concrete was determined as 3105 psi. Workability of concrete were determined using slump cone method, and was found as $35 \mathrm{~mm}$.

\subsection{Specimen Details}

Total six RCC beams were cast for this research work. The size of specimen was kept $3 \mathrm{ft}$ long, 6 inches wide and deep. These beams then divided into two categories, category A and category B based on number of flexural steel. For category A, four steel bars-two at top and two at bottom and for category B, six steel bars-two at top and four at bottom are used. For each category, three beams were caste. Further detail of category and steel arrangement is given in Figure 1(a) and 1(b) and in Table 3. All specimens were cast at same, traditional mix ratio of 1:2:4 and water-cement ratio of 0.50 .

Table 1. Properties of Sikadur-330

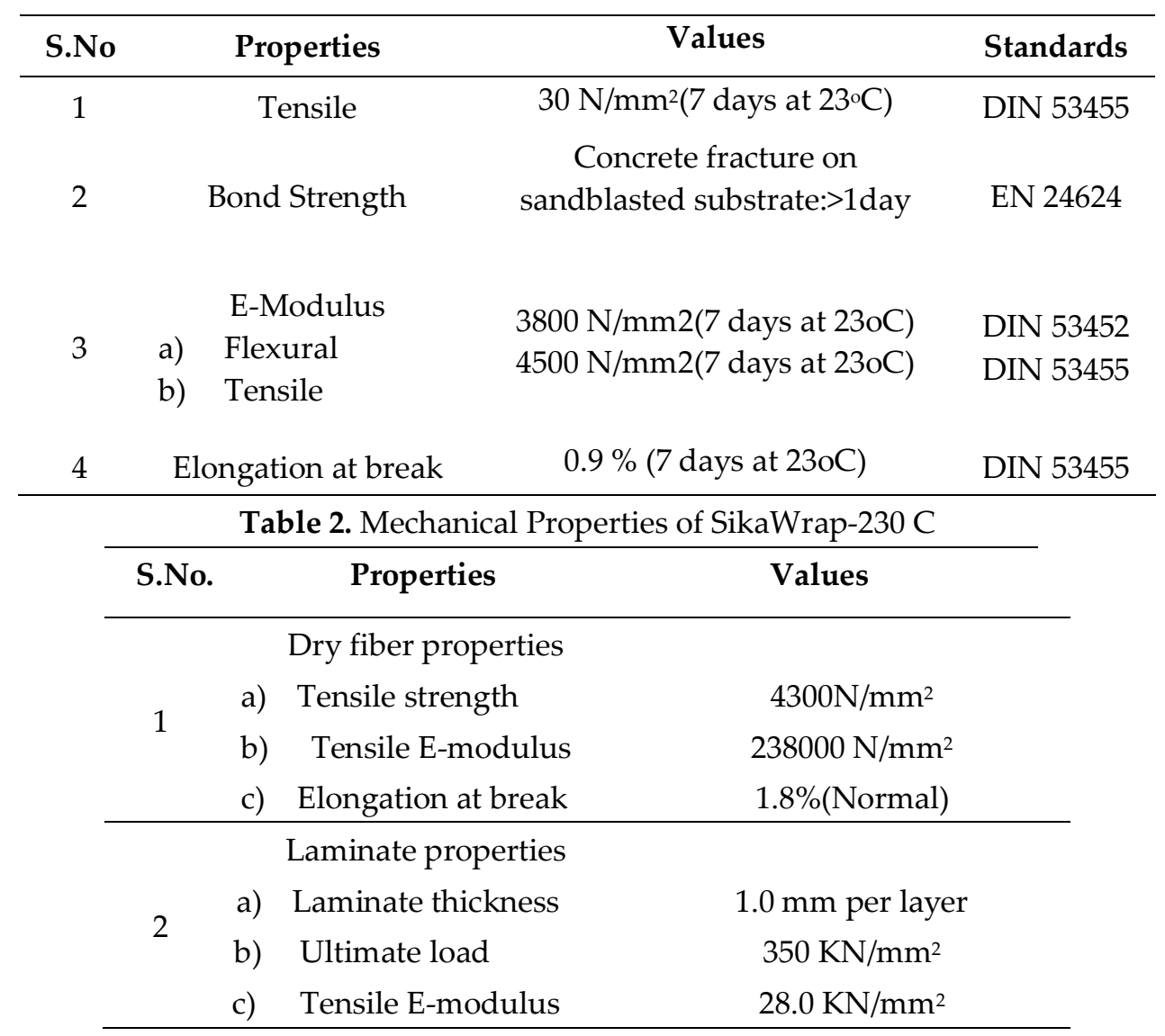



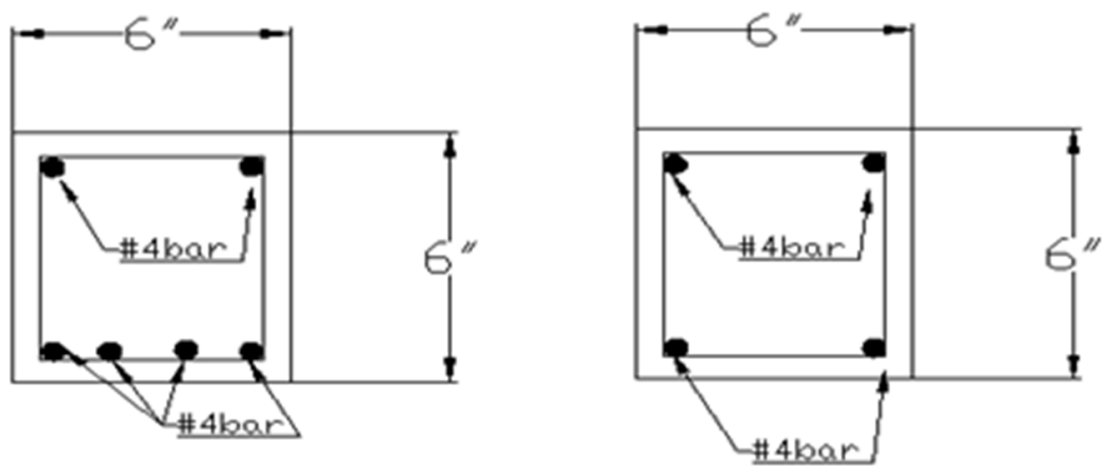

170

Figure 1. (a) Cross section of Category B Figure 1. (b) Cross section of Category A

Table 3. Details of Specimen

\begin{tabular}{|c|c|c|c|c|c|c|c|}
\hline Category & $\begin{array}{l}\text { Beam } \\
\text { Name }\end{array}$ & Beam Type & $\begin{array}{l}\text { No. of } \\
\text { beams }\end{array}$ & $\begin{array}{l}\text { Cross section } \\
\text { (in } x \text { in) }\end{array}$ & $\begin{array}{l}\text { Length } \\
\text { (inches) }\end{array}$ & $\begin{array}{c}\text { Top } \\
\text { Bar }(\# 4)\end{array}$ & $\begin{array}{l}\text { Bottom } \\
\text { Bar (\#4) }\end{array}$ \\
\hline \multirow{3}{*}{ A } & BA-1 & Reference beam & & & & & \\
\hline & BA-2 & $\begin{array}{c}\text { Strengthened beam } \\
\text { with single layer of } \\
\text { CFRP }\end{array}$ & 3 & $6 \times 6$ & 36 & 2 & 2 \\
\hline & BA-3 & $\begin{array}{c}\text { Strengthened beam } \\
\text { with double layer of } \\
\text { CFRP }\end{array}$ & & & & & \\
\hline \multirow{3}{*}{ B } & BB-1 & Reference beam & & & & & \\
\hline & BB-2 & $\begin{array}{c}\text { Strengthened beam } \\
\text { with single layer of } \\
\text { CFRP }\end{array}$ & 3 & $6 \times 6$ & 36 & 2 & 4 \\
\hline & BB-3 & $\begin{array}{c}\text { Strengthened beam } \\
\text { with double layer of } \\
\text { CFRP }\end{array}$ & & & & & \\
\hline
\end{tabular}

173

174

175

176

177

178

179

180

181

182

183

184

185

186

187

Furthermore, beams are also classified based on number of CFRP layers. Out of six beams, two beams (one from category A, named as BA- 1 and one from category B, named as BB-1) were taken as reference or controlled without any fiber layer for comparison purpose. Two beams (one from category A, named as BA-2 and one from category B, named as BB-2) were repaired with single layer of CFRP and other two beams (one from category A, named as BA-3 and one from category B, named as BB-3) were repaired with double layer of CFRP.

After casting, specimens were placed in curing tank for 28 days for proper curing and then tested in Universal Testing Machine (UTM).

\subsection{Testing Methodology}

All beams were tested under three-point load testing procedure of ASTM C 78 in UTM of 1800 KN capacity available at Concrete and Structural Laboratory in Civil Engineering Department, Mehran UET Jamshoro. The specimens were placed on simply supported assembly and deflection gauge was attached with specimen at middle-bottom for measuring the maximum deflection as shown in fig 2. 
Under applied load, these parameters- crack propagation, deflection and failure modes were observed during testing. Initially, reference beams were tested for knowing their ultimate load carrying capacity and load-deflection behavior. Based on load carrying capacity, the remaining four beams were loaded up to $80-90 \%$ of ultimate load of controlled beams accordingly. As soon as eye visible cracks appeared in beams the load was stopped and the load which cases cracks in beam was in the range of $80-90 \%$ of failure load of controlled beams. Further, cracked beams were strengthened using CFRP with single and double layer and re-tested up to failure of repaired beams. During re-testing, again aforementioned parameters were investigated separately.
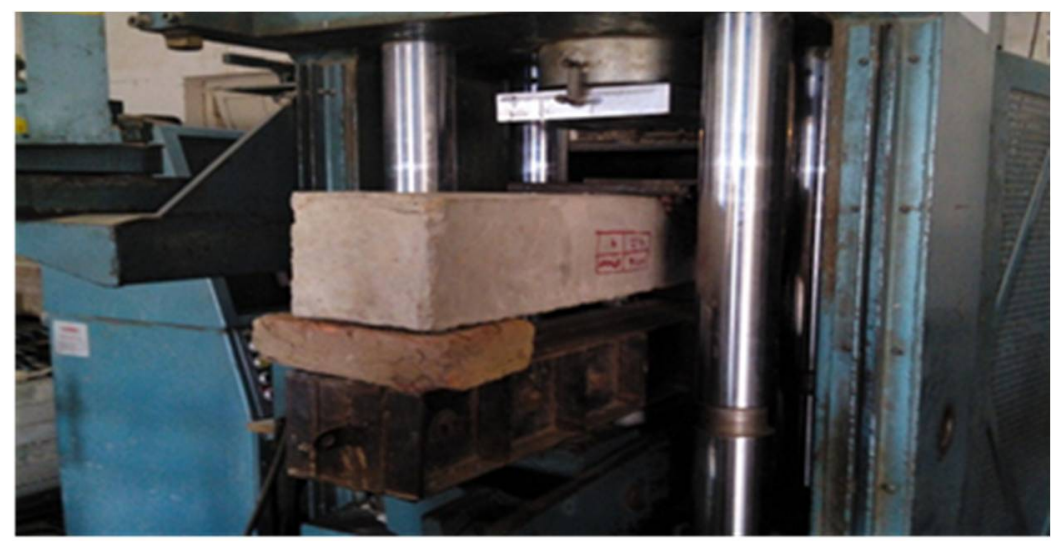

Figure 2. Three- point bending test setup in UTM

\subsection{Repairing Procedure}

The procedure adopted to check the behavior of RCC beams repaired with single and double layer of CFRP. The beams named BA-2 and BB-2 were repaired with single layer of CFRP with SikaWrap-230 C and sikadur-330 (adhesive) material. The fiber was wrapped at the tension zone or bottom face of the beam. The beams BA-3 and BB-3 were repaired with double layer of CFRP with SikaWrap-230 C and same binding material. The epoxy paste of SikaWrap-230 C was applied at the bottom face of the beam as well as on the CFRP sheet using paint brush, after few minutes CFRP sheets-painted with epoxy were wrapped on the bottom face of cracked beam. After pasting one layer of CFRP, the two of four beams were left for 4 hours and then, second layer was applied by adopting same procedure.

\section{Test Results and Discussion}

\subsection{Ultimate Load, maximum deflection and Flexural Strength}

Ultimate load carrying capacity, maximum deflection and flexural strength were investigated for all categories before and after repairing of RCC beams. Table 4 gives all the parameters before repairing of beams with CFRP. Flexural strength increases with increasing steel bars and load carrying capacity at $80-90 \%$ of failure load of controlled beams, of category B is higher than category A, due to more reinforcement. However, deflection increases as load carrying capacity increases. Therefore, more deflection was observed in category B than category A, due to more elastic behavior of specimens having more percentage of reinforcement. 
Table 4. Test results of beams

\begin{tabular}{|c|c|c|c|}
\hline Description of beams & $\begin{array}{l}\text { Failure load(P) } \\
\qquad(\mathrm{KN})\end{array}$ & $\begin{array}{c}\text { Maximum } \\
\text { Deflection } \\
(\mathrm{mm}) \\
\end{array}$ & $\begin{array}{c}\begin{array}{c}\text { Flexural } \\
\text { strength }\end{array} \\
=3 \mathrm{PL} / 2 \mathrm{bd}^{2}(\mathrm{psi})\end{array}$ \\
\hline \multicolumn{4}{|l|}{ Reference Beam } \\
\hline Category A & 73.34 & 13.2 & 18,335 \\
\hline Category B & 78.14 & 13.7 & 19,535 \\
\hline \multicolumn{4}{|c|}{$\begin{array}{l}\text { Beam repaired with single layer of } \\
\text { CFRP }\end{array}$} \\
\hline Category A & 91.2 & 13.8 & 22,800 \\
\hline Category B & 97.75 & 14 & $24,437.5$ \\
\hline \multicolumn{4}{|c|}{$\begin{array}{l}\text { Beam repaired with double layer of } \\
\text { CFRP }\end{array}$} \\
\hline Category A & 94.12 & 14.6 & 23,530 \\
\hline Category B & 101.81 & 14.9 & $25,452.5$ \\
\hline
\end{tabular}

\subsection{Result Analysis of Beam $B A-1$ and $B B-1$}

Beams BA-1 and BB-1 are reference/controlled beams of category A and B respectively. These beams were examined under three-point loading condition up to its complete rupture. As load applied, first hair like flexural crack was appeared at $31.706 \mathrm{KN}$ load in BA-1 and 40.55KN in BB-1. These cracks become widen continuously and new cracks appeared also, with increasing load. And deflection at bottom mid of the beam increases with increasing load. The load-deflection behavior is shown in fig. 03 and 04. It shows the mixed relationship i.e. linear as well as curvature with moderate slope and then it turns to steeper slope as load increases. This increment in slope is due to the yielding of steel, and again graph attains a small linear behavior with steep slope which reveals more load carrying capacity with less deflection. Finally, the beam BA-1 failed in flexure at $73.34 \mathrm{KN}$ load and maximum deflection of $13.2 \mathrm{~mm}$. And beam BB-1 failed in shear, as cutting action was observed at near about one-third of length from both supports at $78.14 \mathrm{KN}$ load with $13.7 \mathrm{~mm}$ deflection at mid span.
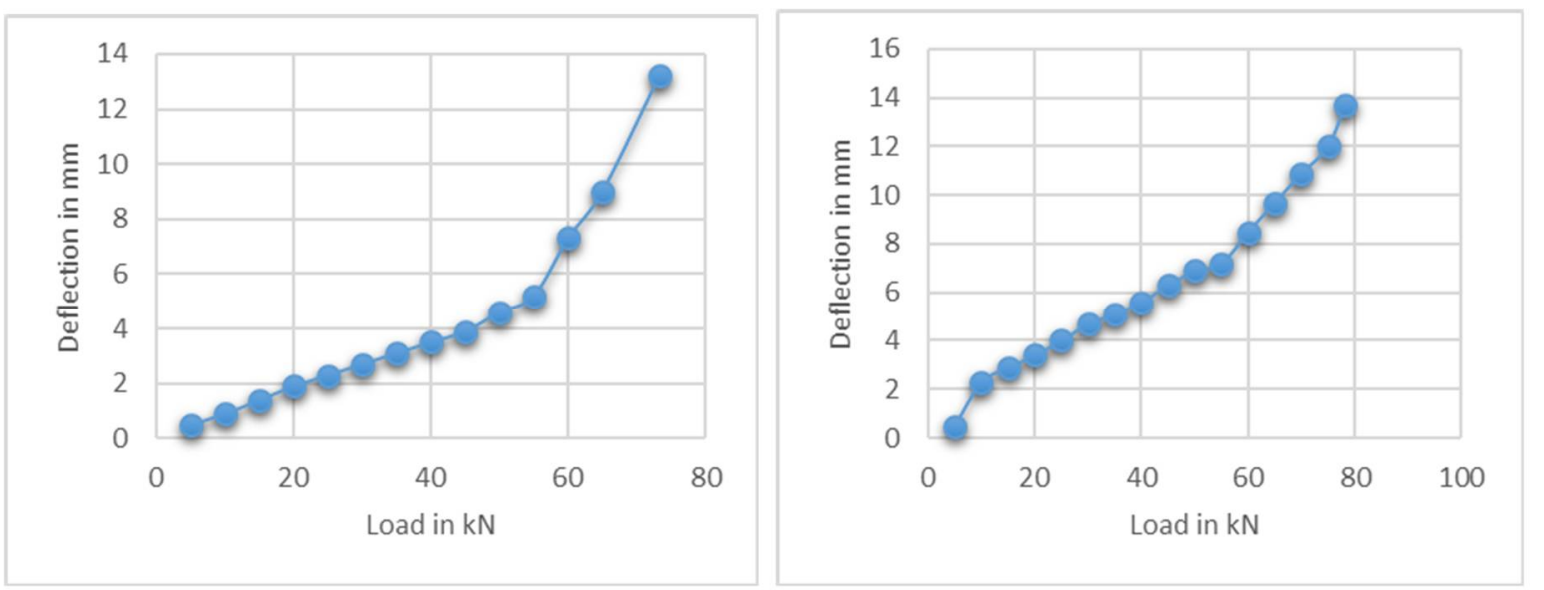

239 Figure 3. Load vs. deflection graph of beam BA-1 Figure: 4. Load vs. deflection graph of beam BB-1

4.3. Result Analysis of Beam BA-2 and BB-2, Repaired with Single Layer of CFRP

The beams BA-2 and BB-2 of catogery A and B respectively were repaired with CFRP and 
and then tested on three point loading. During visual observation with naked eyes, it was noted that the first crack appeared at the load of $71.15 \mathrm{KN}$ in BA-2 and 72.12 KN in BB-2, which shows the increased load carrying capacity of the repaired beams. During loading through UTM, it was noted that no any previous cracks re-opened in both of the beams, which indicates the strong bonding of Sikadur-330 with concrete surface. However, new hair like cracks were observed and with increasing load, number and size of new cracks increases up to load of $90 \mathrm{KN}$ in both beams. Load-deflection behaviour of repaired beams is given in Fig. 5 and 6. As load increased beyond 90 $\mathrm{KN}$, the shear cracks were appeared near by both supports and beams instintly failed in shear at 91.2KN with $13.8 \mathrm{~mm}$ deflection in BA-2 and at 97.75KN with $14 \mathrm{~mm}$ deflection in BB-2. However, load at failure of single layer repaired beams was higher than controlled beams. Load carrying capacity increases up to $24.35 \%$ and $25.09 \%$ in BA-2 and BB-2 respectively.
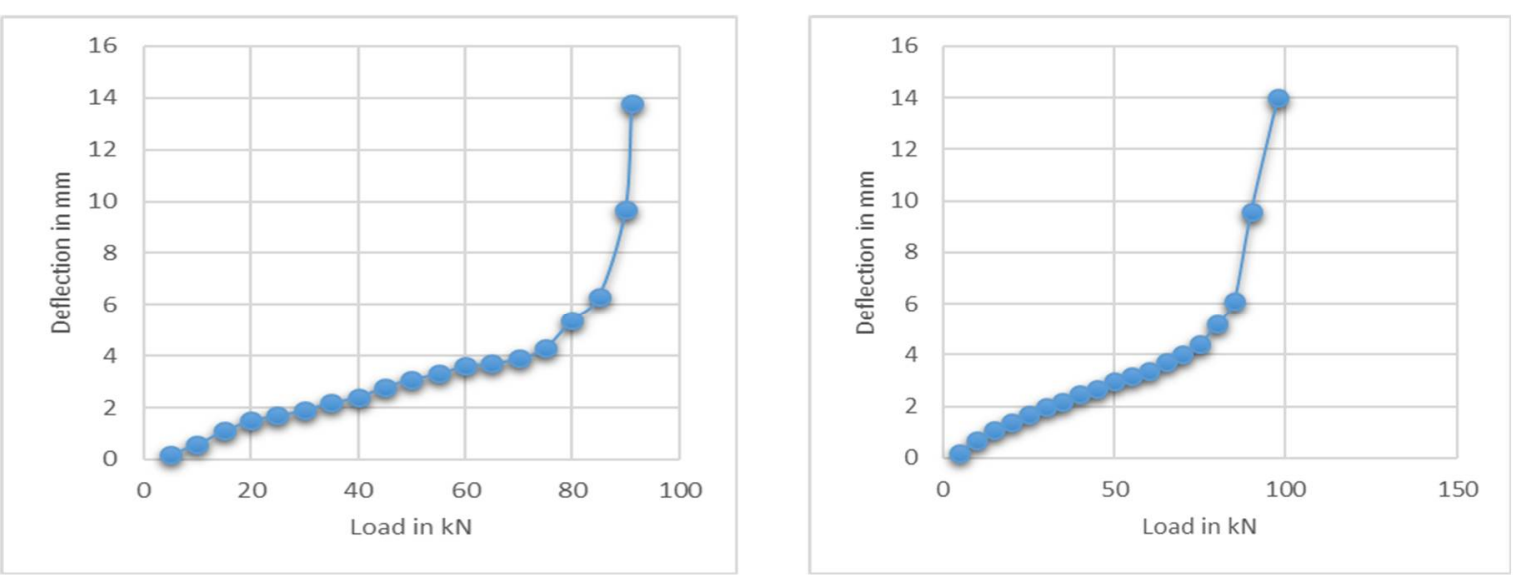

Figure: 5. Load vs. deflection graph of beam BA-2 Figure: 6. Load vs. deflection graph of beam BB-2

\subsection{Result Analysis of Beam BA-3 and BB-3, Repaired with Double Layer of CFRP}

The beams BA-3 and BB-3 of category A and B respectively were repaired with double layers of CFRP and SikaWrap-230 C as binding material (shown in Fig.7). After repairing, load is applied in UTM till its faillure (shown in Fig.8). First hair like crack was noted at the load of $70.4 \mathrm{KN}$ in BA-3 and $86.8 \mathrm{KN}$ in BB-3. Similarly, in this case, no any previous repaired cracks were opened which ensure the binding quality of Sikadur -330 as strong binding material. But, new crack were observed and these cracks increase in number and size as load increases, till load reaches at $95 \mathrm{KN}$ in both beams. As load increased beyond $95 \mathrm{KN}$, shear cracks were appeared suddenly and beams quickly failed in shear at load of $94.12 \mathrm{KN}$ with deflection of $14.6 \mathrm{~mm}$ in BA-3 and load of $101.81 \mathrm{KN}$ with deflection of $14.9 \mathrm{~mm}$ in BB-3. Load-deflection behavior is given in Fig. 9 and 10. Load carrying capacity of repaired beams increases as $28.34 \%$ and $30.29 \%$ for BA-3 and BB-3 respectively.

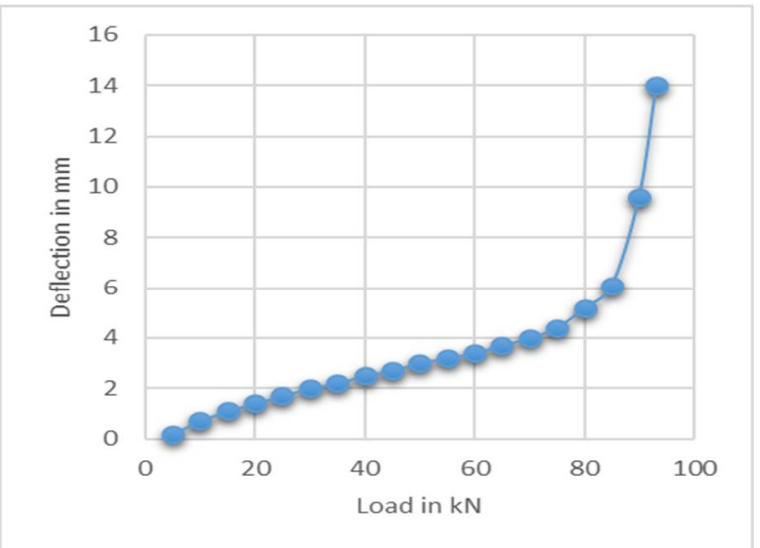

Figure 7. Beam specimen with CFRP

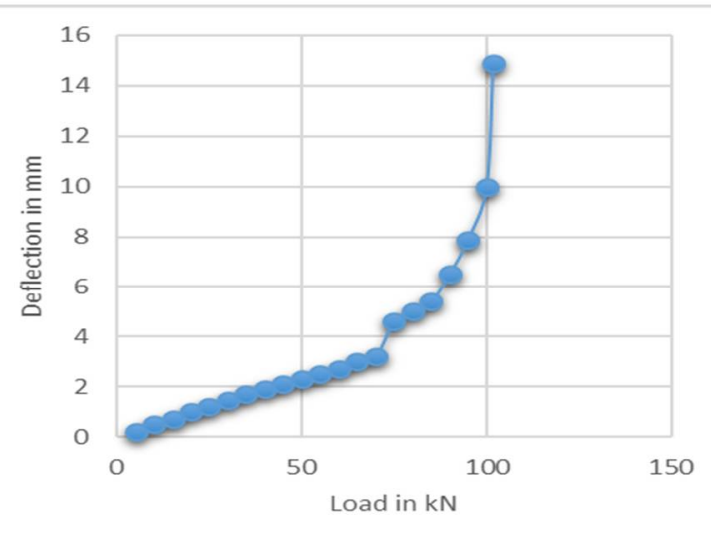

Figure 8. Testing of repaired beam in UTM 


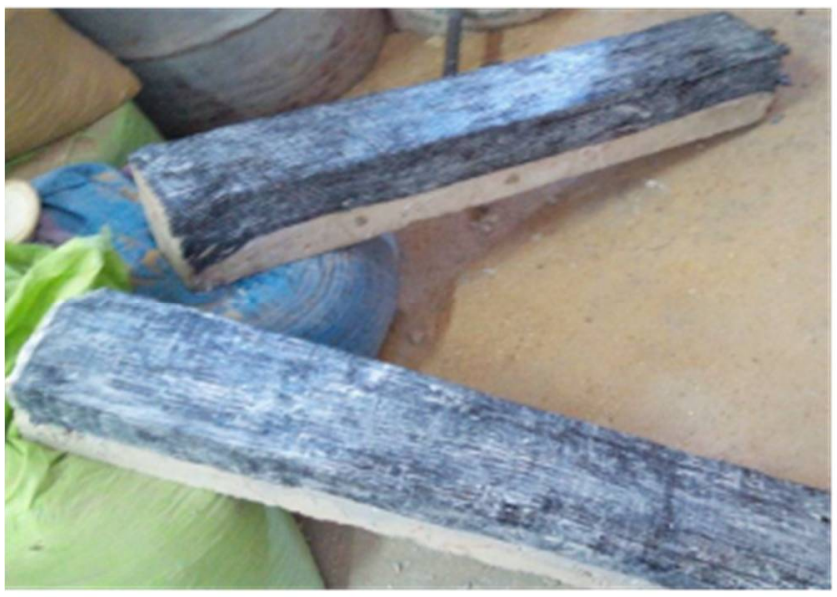

Figure 9. Load vs. deflection graph of beam

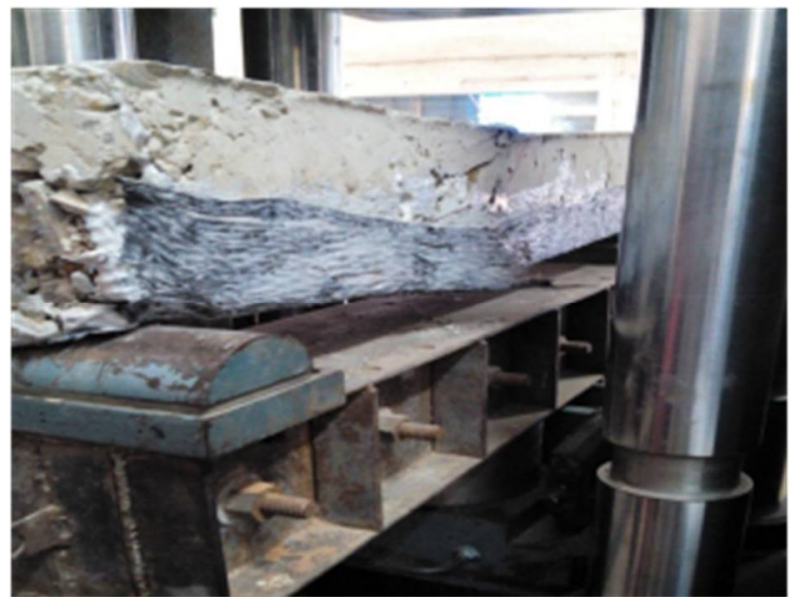

Figure 10. Load vs. deflection graph of beam

\section{Conclusion}

The research work presented herein, was conducted to investigate the behavior of flexural strength of RCC beams, by utilizing layers of CFRP and Epoxy as repairing materials. Based on the experimental investigations, it is concluded that:

- $\quad$ RCC beams repaired with CFRP sustain higher load as compared to reference beams. Hence,

- Flexural strength capacity of single and double layer of CFRP repaired beams increases $24.35 \%$ and $28.34 \%$ respectively, for category A beams.

- Similarly, flexural strength of single and double layer of CFRP repaired beams increases $25.09 \%$ and $30.29 \%$ respectively, for category B beams.

- Sikadur-330 as repairing material is very effective bonding material, it traps the cracks, when applied on concrete surface.

- $\quad$ By providing one additional (second) layer of CFRP, only $4-5.2 \%$ increment in flexural strength was observed.

CFRP is very effective in resisting the flexural cracks. Hence, it can be used for enhancing the flexural strength of RCC beams. However; any significant effect in flexural performance has not been found by providing second layer of fiber. A small increment in deflection was observed by additional layer of fiber.

\section{Future Work}

This work is limited to check the flexural strength of beam repaired with single and double layer of CFRP. However, this study can be enhanced further to check the effect of layer on shear strength. The research can further be carried out to check the layer system on cyclic loading, thermal loading, impact loading and outside environment exposure as well.

Acknowledgments: In this section you can acknowledge any support given which is not covered by the author contribution or funding sections. This may include administrative and technical support, or donations in kind (e.g., materials used for experiments).

Conflicts of Interest: The author(s) declared no potential conflicts of interest with respect to the research, authorship, and/or publication of this article.

Funding: The author(s) received no financial support for the research, authorship, and/or publication of this article. 


\section{References}

1. Arduini, M.; Nanni, A.,. Behavior of Precracked RC beams strengthened with carbon FRP Sheets. Asce J Compos Constr, 1997, 1 (2), 63-70. https://doi.org/10.1061/(ASCE)1090-0268(1997)1:2(63)

2. Yeong-soo, S.; Chadon, L. Flexural behavior of reinforced concrete beams strengthened with carbon fiber-reinforced polymer laminates at different levels of sustaining load. ACI Struct. J. 2003, 100 (2), 231240. https://doi: 10.1061/(ASCE)CC.1943-5614.0000452

3. Bonacci, J.F,; Maalej, M. Externally bonded fiber-reinforced polymer for rehabilitation of corrosion damaged concrete beams, 2000. ACI Struct. J. 97 (5), 703-711.

https://www.concrete.org/publications/internationalconcreteabstractsportal/m/details/id/8805

4. Shahawy, M.; Chaallal, O.; Thomas, E.B.; Adnan, E. Flexural strengthening with carbon fiber-reinforced polymer composites of preload full-scale girders, 2001. ACI Struct. J. 98 (5), 735-743. DOI । 10.1061/(ASCE)CC.1943-5614.0000604

5. Soudki, K.; Alkhrdaji, T. Guide for the design and construction of externally bonded FRP systems for strengthening concrete structures (ACI 440.2 R-02). In Structures Congress 2005: Metropolis and Beyond 2005, pp. 1-8. https://doi.org/10.1061/40753(171)159

6. Pellegrino $C_{\text {; }}$, D'Antino T. Experimental behaviour of existing precast prestressed reinforced concrete elements strengthened with cementitious composites. Compos Part B Eng. 2013, 55, 31-40. https://doi.org/10.1016/j.compositesb.2013.05.053

7. Omrane. B.; Mongi, B. O.; Aouicha, B. Damaged RC beams repaired by bonding of CFRP laminates, J. Constr. Buil. Mater. 2007, 21, 1301-1310. https://doi.org/10.1016/j.conbuildmat.2006.01.008

8. Saadatmanesh, H.; Ehsani MR. Reinforced concrete beams strengthened with GFRP plates-I. $\begin{array}{llllll}\text { Experimental study. } \quad \text { J. Struct. } & \text { Eng. 1991, 117(11):3417-33. }\end{array}$ https://doi.org/10.1061/(ASCE)0733-9445(1991)117:11(3417).

9. Ritchie, PA.; David, AT.; Le-Wu, L.; Guy, MC. External reinforcement of concrete beams using fiber $\begin{array}{lllll}\text { reinforced } & \text { plastics. } & \text { Struct. 1991, 88(4):490-500. }\end{array}$ https://preserve.lehigh.edu/cgi/viewcontent.cgi?article=1159\&context=engr-civil-environmental-atlss-repo $\underline{\text { rts }}$

10. Meier. U.; Kaiser, HP. Strengthening of structures with CFRP laminates. In: Proceedings on advanced composite materials in civil engineering structures, MT. Div./ASCE/Las Vegas, 1991, p. $224-32$. doi:10.1016/S0950-0618(03)00094-1

11. Jones, R.; Swamy, R. N.; Bloxham, J.; Bouderbalah, A.; Composite behavior of concrete beams with epoxy bonded external reinforcement, Int. J. Cem. Compos. 1980, 2 (2), 91-107. https://trove.nla.gov.au/version/46272700

12. Saadatmanesh, H.; Ehsani, M. RC beams strengthened with GFRP plates. Part I and Part II. J. Struct. Eng. 1991, 117 (11), 3417-3455. https://doi.org/10.1061/(ASCE)0733-9445(1991)117:11(3417)

13. Charles, W.D. FRP prestressing in the USA. Concr. Int. 1999, 10, 21-24. https://www.concrete.org/publications/internationalconcreteabstractsportal/m/details/id/713

14. Arduini, M.; Nanni, A. Behavior of Precracked RC beams strengthened with carbon FRP Sheets. J. Compos. Constr. 1997, 1 (2), 63-70. https://doi.org/10.1061/(ASCE)1090-0268(1997)1:2(63)

15. Norris, T.; Saadatmanesh, H.; Mohammad, R. E. Shear and flexural strengthening of R/C beams with carbon fiber sheets, J. Struct. Eng. 1997, 123 (7), 903-911. https://doi.org/10.1061/(ASCE)0733-9445(1997)123:7(903)

16. Yao, J., Teng, JG. Plate end de-bonding in FRP-plated RC beams-I: experiments, Eng. Struct. 2007, 29 (10), 2457-71. https://doi.org/10.1016/j.engstruct.2006.11.022

17. Ekenel, M.; Myers, J. J. Durability performance of RC beams strengthened with epoxy injection and CFRP fabrics, Constr. Build. Mater. 2007, 21(6), 1182-1190. https://doi.org/10.1016/j.conbuildmat.2006.06.020

18. Burningham, C. A.; Pantelides, C. P.; Reaveley, L. D. Repair of reinforced concrete deep beams using post-tensioned CFRP rods, Compos. Struct. 2015, 125, 256-265. https://doi.org/10.1016/j.compstruct.2015.01.054

19. Benjeddou, O.; Ouezdou, M. B.; Bedday, A. Damaged RC beams repaired by bonding of CFRP laminates, Constr. Build. Mater. 2007, 21(6), 1301-1310. https://doi.org/10.1016/j.conbuildmat.2006.01.008

20. Tahsiri, H.; Sedehi, O.; Khaloo, A.; Raisi, E. M. Experimental study of RC jacketed and CFRP strengthened RC beams, Constr. Build. Mater. 2015, 95, 476-485. https://doi.org/10.1016/j.conbuildmat.2015.07.161 
355

356

357

358

359

360

361

362

363

364

365

366

367

368

369

370

371

372

373

374

375

376

377

378

379

380

381

382

383

384

385

386

387

388

389

390

21. Liu, S.; Cheng, X.; Zhang, Q.; Zhang, J.; Bao, J.; Guo, X. An investigation of hygrothermal effects on adhesive materials and double lap shear joints of CFRP composite laminates, Composites Part B, 2016, 91, 431-440. https://doi.org/10.1016/j.compositesb.2016.01.051

22. Limam, O.; Foret, G.; Ehrlacher, A. RC two-way slabs strengthened with CFRP strips: experimental study and a limit analysis approach, Compos. Struct. 2003, 60(4), 467-471. https://doi.org/10.1016/S0263-8223(03)00011-4.

23. Thanoon, W. A.; Jaafar, M. S.; Kadir, M. R. A.; Noorzaei, J. Repair and structural performance of initially cracked reinforced concrete slabs, Constr. Build. Mater. 2005, 19(8), 595-603. https://doi.org/10.1016/j.conbuildmat.2005.01.011.

24. Wenwei, W.; Guo, L. Experimental study and analysis of RC beams strengthened with CFRP laminates under sustaining load, Int. J. Solids Struct. 2006, 43(6), 1372-1387. https://doi.org/10.1016/j.ijsolstr.2005.03.076.

25. Haber, Z. B.; Mackie, K. R.; Zhao, L. Mechanical and environmental loading of concrete beams strengthened with epoxy and polyurethane matrix carbon fiber laminates, Constr. Build. Mater. 2012, 26(1), 604-612.

26. Morsy, A.; Mahmoud, E. T. Bonding techniques for flexural strengthening of RC beams using CFRP laminates, Ain Shams Eng. J. 2013, 4(3), 369-374. https://doi.org/10.1016/j.asej.2012.11.004.

27. Ferrari, V. J.; de Hanai, J. B.; de Souza, R. A. Flexural strengthening of reinforcement concrete beams using high performance fiber reinforcement cement-based composite (HPFRCC) and carbon fiber reinforced polymers (CFRP), Constr. Build. Mater. 2013, 48, 485-498. https://doi.org/10.1016/j.conbuildmat.2013.07.026.

28. Capani, F.; D'Ambrisi, A.; De Stefano, M.; Focacci, F.; Luciano, R.; Nudo, R.; Penna, R. Experimental investigation on cyclic response of RC elements repaired by CFRP external reinforcing systems, Composites Part B, 2017, 112, 290-299. https://doi.org/10.1016/j.compositesb.2016.12.053.

29. Karam, E. C.; Hawileh, R. A.; El Maaddawy, T.; Abdalla, J. A. Experimental investigations of repair of pre-damaged steel-concrete composite beams using CFRP laminates and mechanical anchors, Thin Walled Struct. 2017, 112, 107-117. https://doi.org/10.1016/j.tws.2016.12.024.

30. Zhang, X.; Wang, P.; Jiang, M.; Fan, H.; Zhou, J.; Li, W.; Jin, F. CFRP strengthening reinforced concrete arches: Strengthening methods and experimental studies, Compos. Struct. 2015, 131, 852-867. https://doi.org/10.1016/j.compstruct.2015.06.034.

31. D'Ambrisi, A.; Focacci, F.; Luciano, R. Experimental investigation on flexural behavior of timber beams repaired with CFRP plates, Compos. Struct. 2014, 108, 720-728. https://doi.org/10.1016/j.compstruct.2013.10.005.

32. Mahmoud, M. H.; Afefy, H. M.; Kassem, N. M.; Fawzy, T. M. Strengthening of defected beam-column joints using CFRP, J. Adv. Res. 2014, 5(1), 67-77. https://doi.org/10.1016/j.jare.2012.11.007. 